\title{
Urban water infrastructure planning of regeneration works in the city of Lorca after the earthquake of 2011 and floods of 2012
}

\author{
S. García-Ayllón \\ Technical University of Cartagena, UPCT, Spain
}

\begin{abstract}
The earthquakes of May 11, 2011 and the floods of September 28, 2012 in the city of Lorca caused most damage to the buildings and urban water infrastructure. To perform reconstruction and urban regeneration in the city, the Ministry of Publics Works and Territorial Management of the Region of Murcia and Lorca Town Hall have planned an important set of urbanization and infrastructure works through funds from the European Investment Bank.

These works are primarily intended for the repair of the urban water infrastructure (water supply and sanitation networks) damaged by the earthquake and the construction of new flood control systems (collectors, storm tanks, etc.) within the city. The process has been developed through a detailed study of the damage caused by the quake in underground infrastructures throughout the city and assessing the risks of flooding in the urban plot for different return periods.

This paper shows the two main results of these studies. On one hand, the process of urban planning of the works performed will be analysed, following the structure of neighbourhoods in the city of Lorca and using GIS assessment methods of flood risk. On the other hand, the most interesting solutions related to new water infrastructure will be presented which will help to improve the response of the city against future floods.

Keywords: urban water planning, flood management, Lorca, urban works.
\end{abstract}

\section{Introduction}

The city of Lorca (Spain) was recently devastated by the earthquakes of May 11, 2011 and the floods of September 28, 2012 (Fig. 1). 


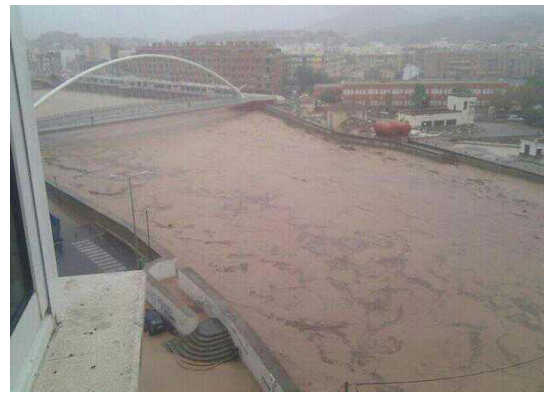

(a)

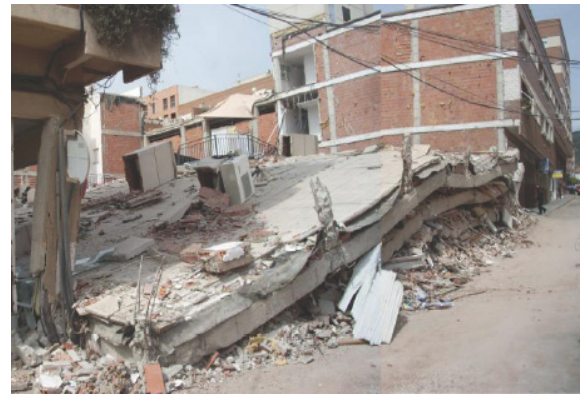

(b)

Figure 1: (a) Guadalentin River as it passes through the Lorca on 28/09/12; (b) Collapsed building after the earthquake of $11 / 05 / 2011$ (source: $[1,2])$.

In the case of earthquakes, the damage was concentrated in buildings, whereas, in the case of floods; the damage was more widespread, affecting a wide range of urban infrastructure, many of which proved not to be sufficiently prepared for rains of these characteristics (Fig. 2).

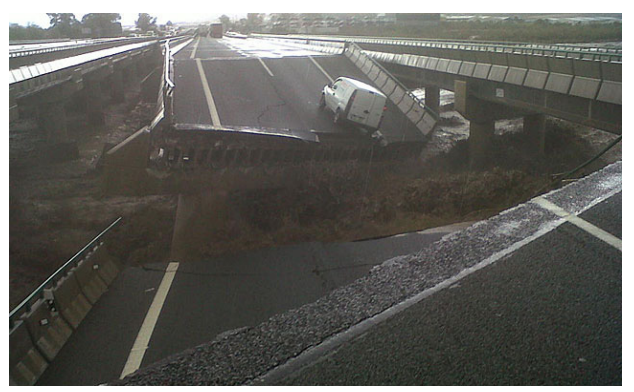

(a)

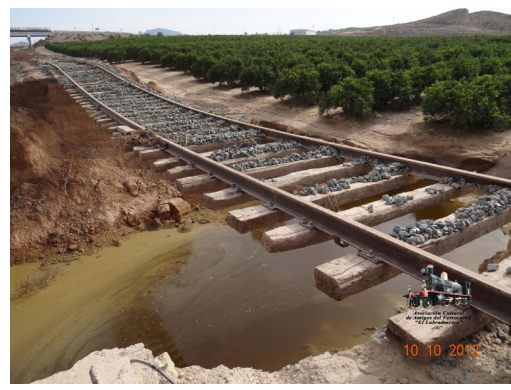

(b)

Figure 2: (a) A-7 Highway Lorca-Murcia and (b) the railway Lorca-Águilas, after the floods of 28/09/2012 (source: [1]).

In order to repair earthquake damage and prepare the city for future floods, the Lorca City Council and the Government of the Region of Murcia through the Ministry of Public Works and Planning have launched a plan funded by a loan from the European Bank for Infrastructure valued at 185 million Euros.

The objective of this project is twofold: first, to repair earthquake damage in the public space of the city of Lorca, and secondly, to improve the urban infrastructure to prepare it better for future disasters. The main action in this great project was the renovation of the main urban areas of the city, repairing and improving the sanitation facilities and water supply, where the damage caused by the earthquake of 2011 could be seen in the malfunction of infrastructure stormwater drainage in 2012. The shallow epicentre of the earthquake (located just 1 kilometer deep), fundamentally damaged groundwater and stormwater drainage networks in the city, as could be verified a year later. 


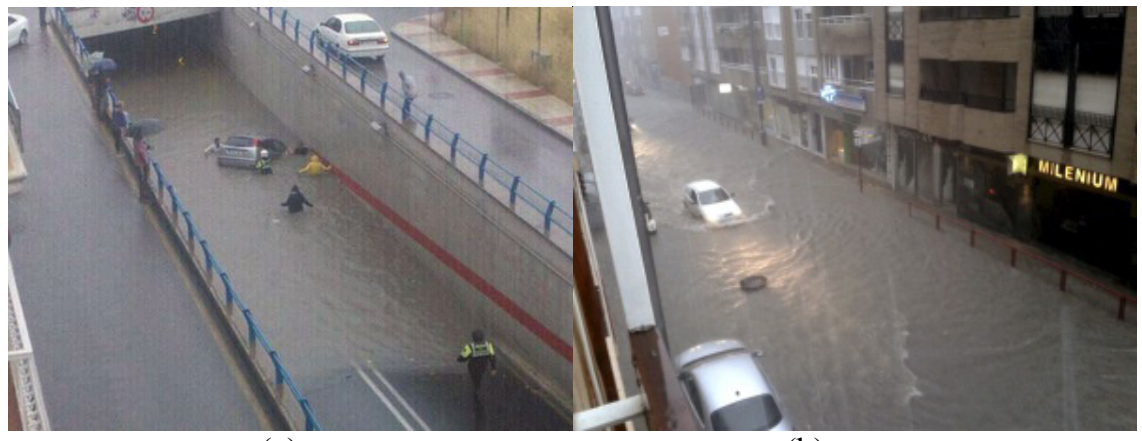

(a)

(b)

Figure 3: (a) Flooded urban tunnels and (b) streets with a water height greater than one meter on 28/09/2012 (source: [1]).

\section{Work analysis and planning: GIS flooding maps}

This problem is not new in Lorca, but had already had a precedent in the St. Wenceslas flooding on October 191973 (Fig. 4). Since then, regardless of the risk of flooding, the city has grown so the work was organized to take into account the urban structure and planning of the city.

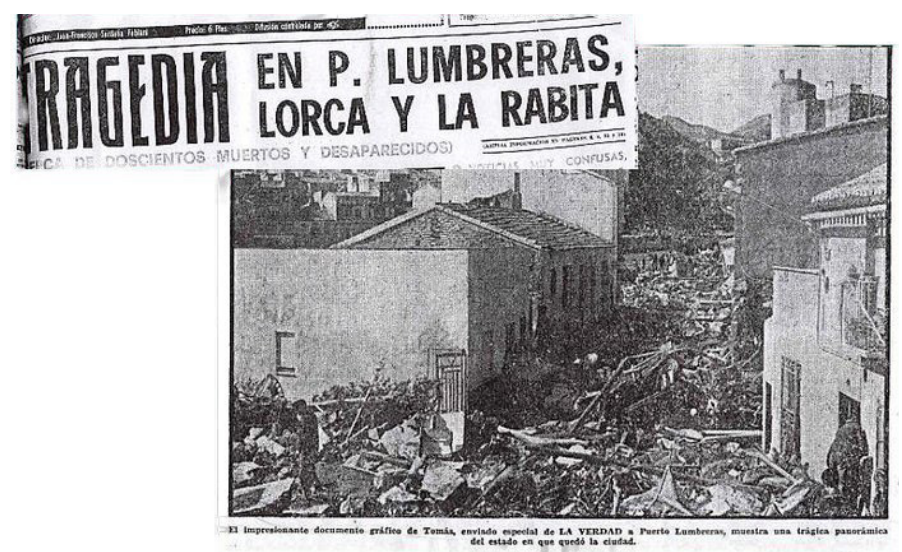

Figure 4: News of the floods of 1973 in Lorca with 89 dead, $2501 / \mathrm{m}^{2}$ rainfall and flow rates of $3000 \mathrm{~m}^{3} / \mathrm{s}$ of water that reached more than 10 meters in height (source: [3]).

This plan has been coordinated between the administrations concerned about works organized according to the urban structure and network infrastructure that provides the general urban plan of the city of Lorca. The city is divided into neighbourhoods, where most of the population is concentrated between the socalled highland districts (set around the mountainside of the medieval castle) and the lowland orchard located around the Guadalentin River (Fig. 5). 


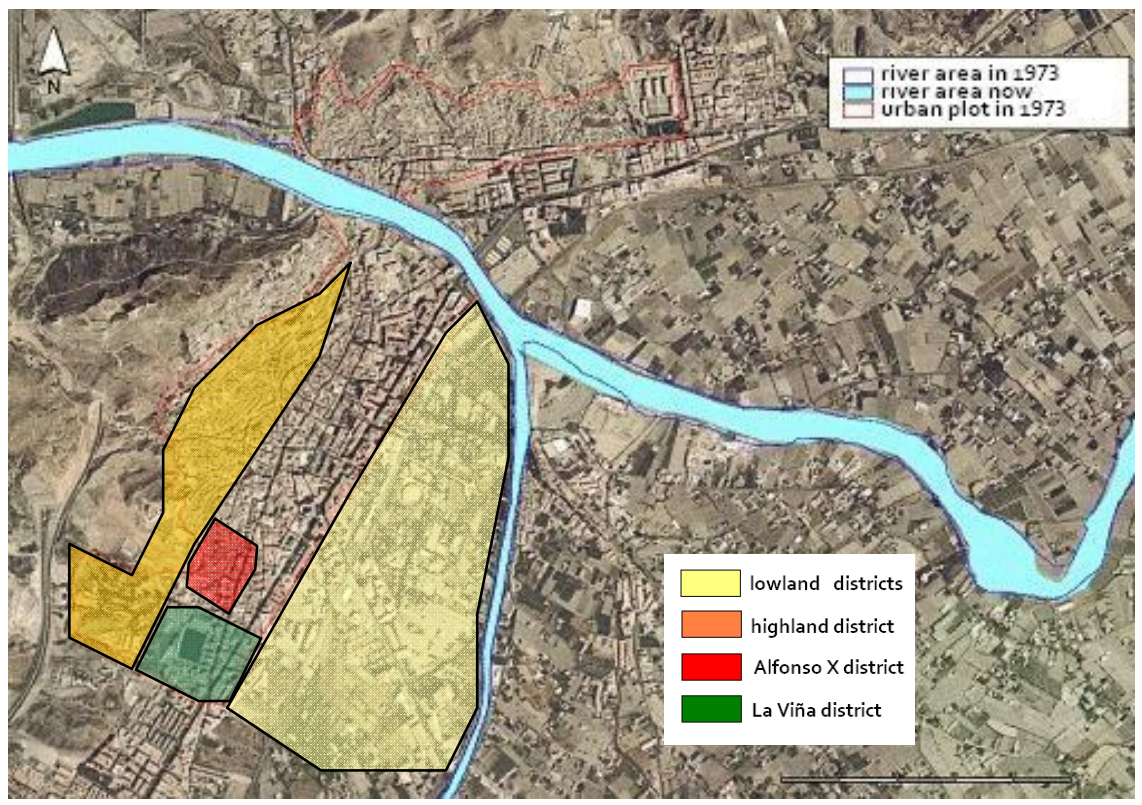

Figure 5: Urban plot analysis performed for the organization of the infrastructure regeneration works in Lorca.

The urban regeneration and repair of infrastructure has been focused on these intermediate districts, badly damaged by the earthquake of 2011, starting with the districts of La Viña and Alfonso X. The structure of these neighbourhoods has been adapted through the GIS study of flooding in streets in this intermediate surface, where water flows from watersheds located in upper districts up to the orchard areas. This analysis was undertaken using georeferenced modelling software that adapts urban plots to areas of potential significant flood risk (Fig. 6).

In November 2007, the European Commission adopted the directive 2007/60 on the assessment and management of flood risks, which is a model to manage these risks. This directive has been transposed into Spanish law by Royal Decree 903/2010 assessment and management of flood risks [4]. This Royal Decree defines in Article 3-m a flood zone as being land that could be flooded by theoretical levels to reach flood waters whose statistical return period is 500 years and establishes the need to identify areas with an increased risk of flooding, known as areas of potential significant flood risk (ARPSIS) and perform them in hazard and flood risk maps of the following scenarios [5]:

a) High probability of flooding, where appropriate.

b) Average probability of flooding (period greater than or equal to 100 years return).

c) Low probability of flooding or extreme event scenarios (return period exceeding 500 years).

GIS tools used for flood risk analysis based on these hazard maps of the areas identified in preliminary assessments as Potential Areas of Significant Flood 


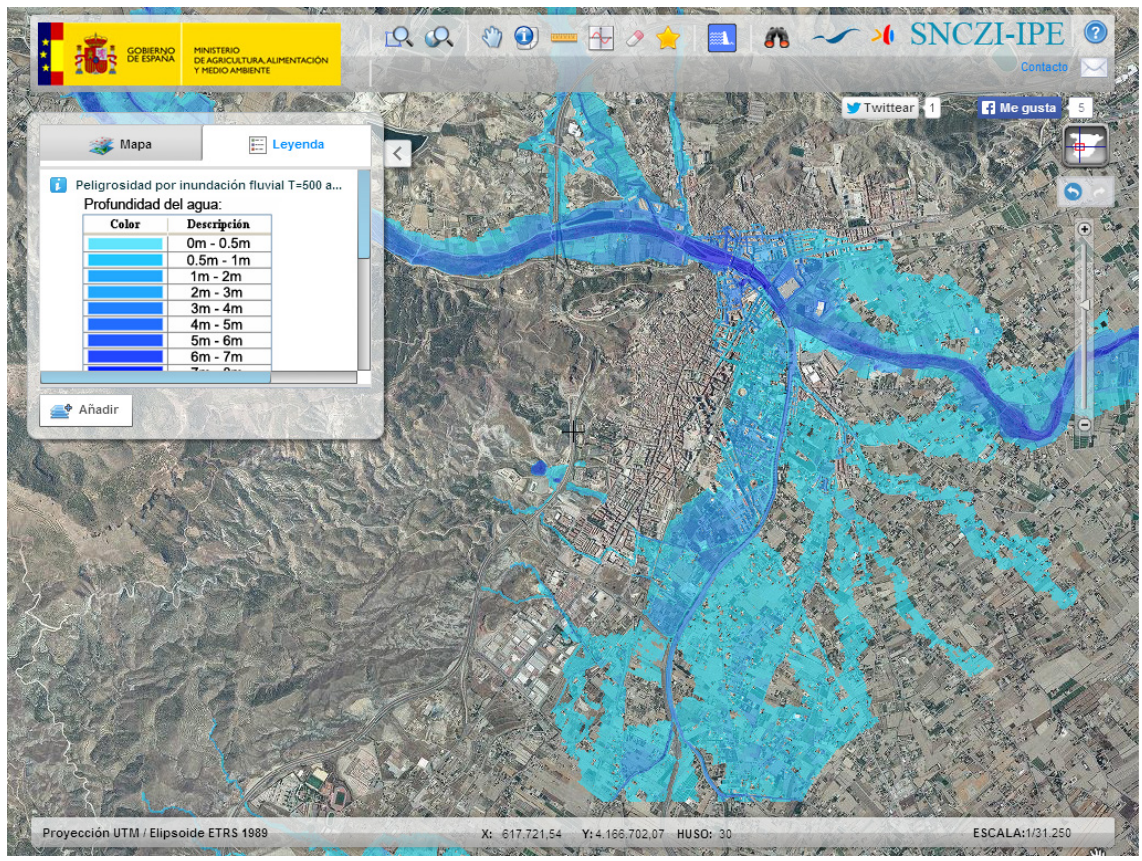

Figure 6: High flooding GIS map of the city of Lorca for different forecasts of water with the return period $\mathrm{T}=500$ years.

Risk (ARPSIs). These studies have been undertaken in each River Basin Watershed by the competent authorities on water, coasts and civil protection in accordance with the procedure laid down in Article 8 of Royal Decree 903/2010. Hazard maps include the three scenarios based on the statistical probability of occurrence of flooding: high probability (associated with a return period equal to 10 years) to be performed when appropriate mean probability (associated with a return period of 100 years) and low probability of flooding or extreme event scenarios (return period exceeding 500 years).

Regarding the concept of return period in the modelling, it is important to perform certain clarifications. In numerical terms, it must be stressed that it is equivalent to the probability that a city present a rate equal to or greater flood in a given year, i.e., the probability that the flow is exceeded in a year. For example, for a return period of 500 years, the probability $\mathrm{F}(\mathrm{x})=1 / \mathrm{T}=1 / 500=$ $0.002=0.2 \%$. Therefore, there is a $0.2 \%$ chance of the flow value of one year being exceeded, and $99.8 \%$ probability that it is not exceeded. However, that does not mean that two or more such avenues or higher intensity within the same year will not occur; the return period, as a statistical concept, depends on the length of the interval considered. In case we want to calculate the probability that equals or exceeds this value for a period of $\mathrm{N}$ years (statistical concept of risk), it would be calculated by the following expression $F(x)=1-[1-(1 / T)]^{N}$. According to the following table, an area affected for example by the flood of return period $\mathrm{T}=500$ years would have $4.9 \%$ chance of being flooded in a period of 25 
Table 1: $\quad$ Probability of occurrence for different return periods depending on the consecutive years analyzed in the modelling.

\begin{tabular}{|c|c|c|c|c|c|c|}
\hline \multirow{2}{*}{ Probability of occurrence (\%) for } & \multicolumn{7}{|c|}{ Consecutive years } \\
\cline { 2 - 8 } & 1 & 2 & 5 & 25 & 50 & 100 \\
\hline $\mathrm{T}=10$ years & 10 & 19 & 41 & 92.8 & 99.5 & 100 \\
\hline $\mathrm{T}=50$ years & 2.0 & 4.0 & 9.6 & 39.7 & 63.6 & 86.7 \\
\hline $\mathrm{T}=100$ years & 1.0 & 2.0 & 4.9 & 22.2 & 39.5 & 63.4 \\
\hline $\mathrm{T}=500$ years & 0.2 & 0.4 & 1.0 & 4.9 & 9.5 & 18.1 \\
\hline
\end{tabular}

consecutive years and $9.5 \%$ chance of flooding in 50 consecutive years (Table 1).

It should be noted in the same way that calculated flood areas have significant limitations regarding the flooding that would occur in a particular event. Current techniques, although very accurate, have significant limitations that could make the real flood event vary significantly from the calculated one. In this sense, for example, two important limitations must be underlined.

The first is that the effects of abrasions, landslides, sedimentation, etc., are only taken into account by using geomorphologic criteria. In a particular situation, especially in sections of steep slopes, geomorphologic changes can be very significant and the results may differ more significantly than expected.

The second is that the existing mathematical models cannot take into account the effects that certain elements may be produced by flow obstructions and derivations, e.g. fallen trees, cars, etc. that can obstruct bridges, roads, etc. deriving the flow in either direction; this being unpredictable.

It is also important to emphasize that, in cases of large flood areas with significant urban settlements (concentrated and dispersed) as those studied in Lorca, the difficulties in adequately representing in the hydraulic model all the artificial elements that influence the flow characteristics. In the same way, the computational constraints imposed by the large amount of processed data, may also cause real results to differ from the flood forecasting model.

\section{Example 1 of actuation: channelling the watercourse of the Señoritas in the neighbourhood of La Viña}

With risk studies in the city at GIS level, different actions have been established [6]. These actions were structured according to the urban plot of Lorca by the criteria of large scale planning. An interesting first example in this regard is the work done in the neighbourhood of La Viña (Fig. 7).

This neighbourhood had two problems. On the one hand, damage to sanitation and stormwater networks by the earthquake of 2011, which were revealed in the floods of 2012. On the other, the problems of overflow in the socalled watercourse de las Señoritas passing through the neighbourhood. Both problems were solved with an integrated regeneration; rearranging the hydraulic infrastructure hierarchy in the district and including the channelling of the wadi (Fig. 8). 


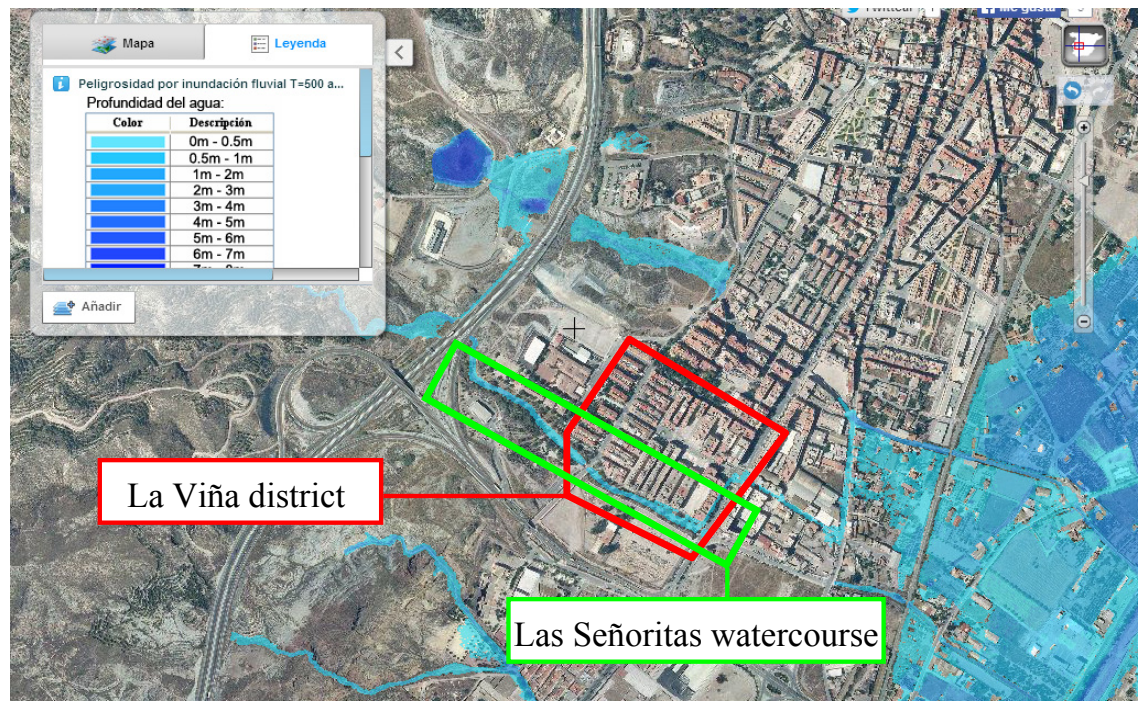

Figure 7: Needs assessment in the neighbourhood of La Viña.

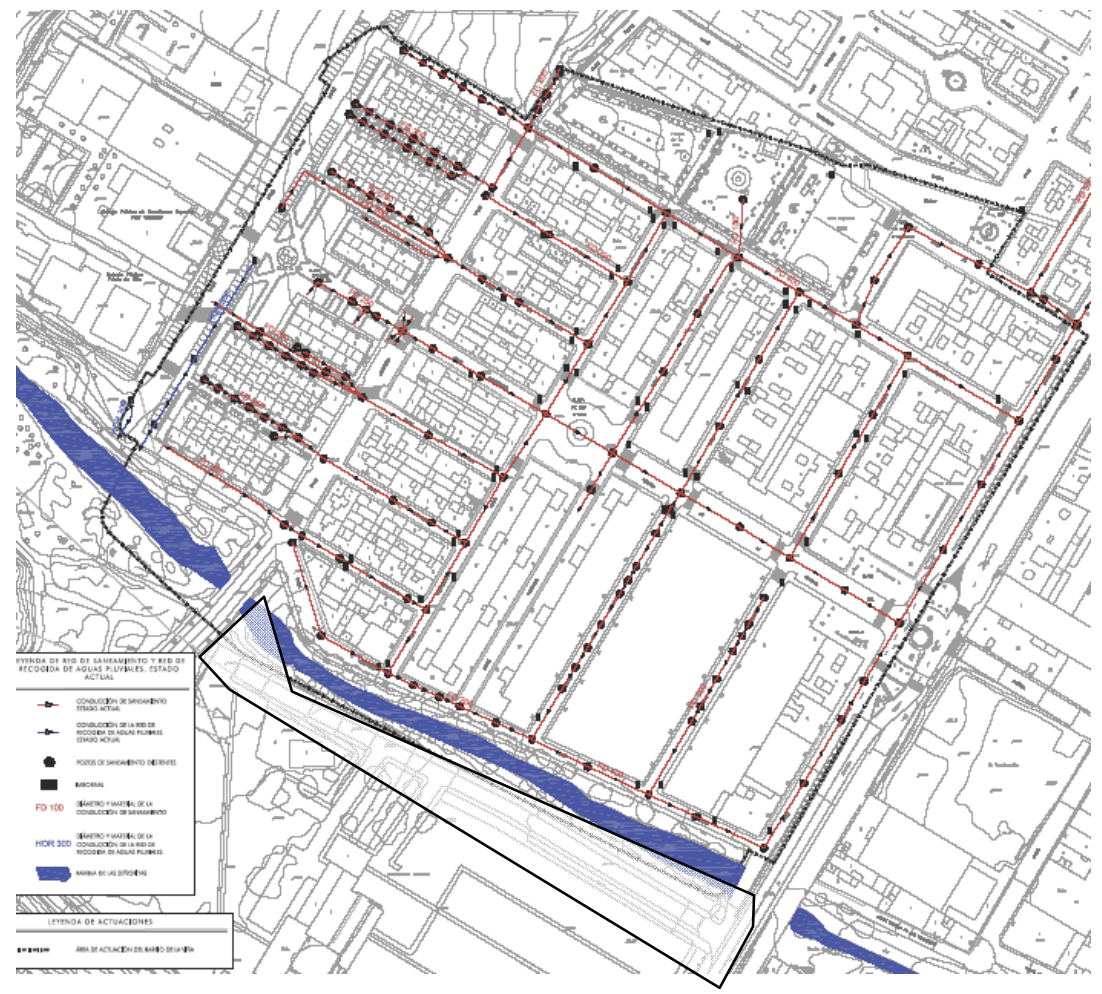

Figure 8: Integrated action rearranging the hydraulic infrastructure of the neighbourhood of La Viña and the channelling of the wadi. 


\section{Example 2 of actuation: new stormwater collectors in the neighbourhood of Alfonso X}

Another interesting case is the neighbourhood of Alfonso X. This district, situated between the so-called Uptown and the lowlands of orchard is a required step area for runoff from the usual torrential rains of autumn in the Mediterranean. The flow rates achieved are usually important even for low return periods due to the lack of rain collectors and separation hydraulic network. The only existing infrastructure is a unitary network of sanitation unit that collects all the rainwater of the neighbourhood only at its outer perimeter in Granada road N-340. The existing network of small, old asbestos-cement pipes, besides being undersized, was damaged by the earthquake of 2011. This entire situation required an in depth performance review, going further than the one executed in the neighbourhood of La Viña.

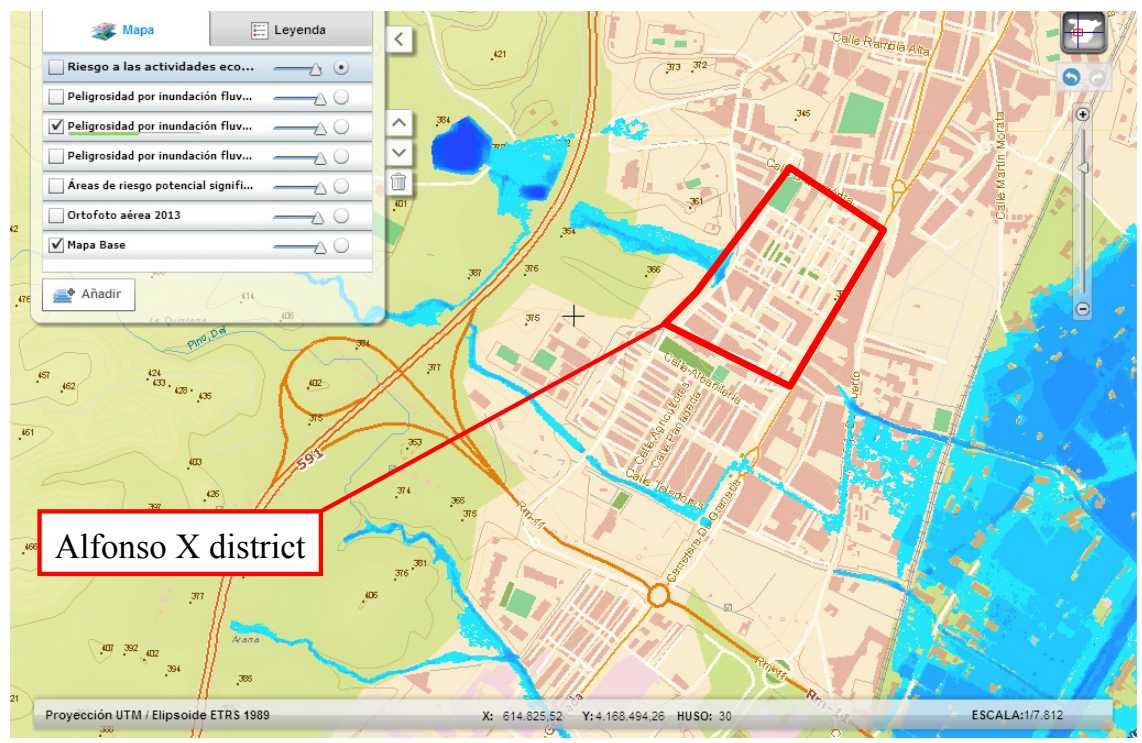

Figure 9: GIS Analysis of flow origin in the neighbourhood of Alfonso X.

The first task was to determine the actual watershed affecting the neighbourhood Alfonso X. The watershed which provided runoff flows extended its surface to several kilometres north of the neighbourhood, beyond the city and beyond the A-7 highway (Fig. 9), with a reduced concentration time. The study of the real watershed allowed sizing three $1500 \mathrm{~mm}$ collectors crossing the neighbourhood and discharging to a large $2000 \mathrm{~mm}$ collector running along the Viejo Camino del Puerto Avenue to the Señoritas watercourse (Fig. 10). 


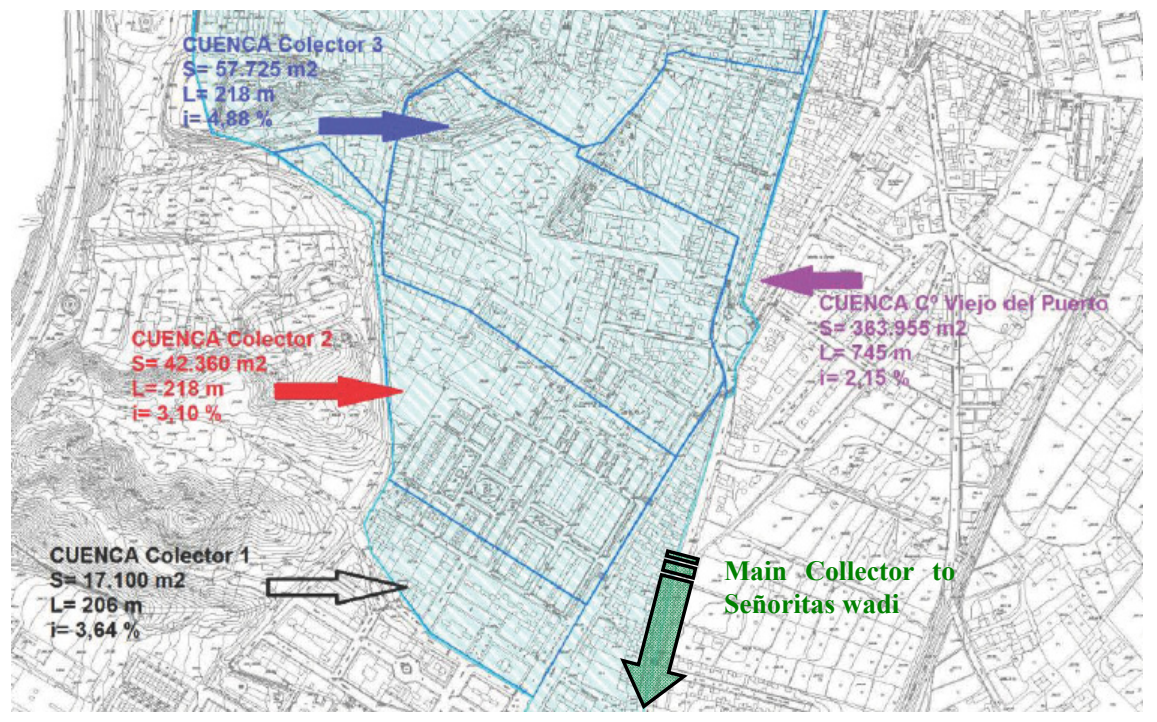

Figure 10: Collectors design and planning in the Alfonso X district.

\section{Conclusions}

Studies done by the Department of Public Works and Planning and the Technical University of Cartagena in Lorca have concluded that damage caused by the 2011 earthquake to the urban water infrastructure of the city largely contributed to the poor response obtained by such infrastructure in the flooding in 2012. This situation forced the Region of Murcia to undertake an integrated work plan repairing infrastructures of the city.

In the different later urban regeneration works undertaken, the importance of using urban planning GIS tools for the design and hierarchization of the new infrastructure should be highlighted. In this field, the determination of real urban watersheds, the correct modelling of flows and the implementation of flood risk maps in the urban area for different return periods are critical for the proper sizing and ordination of urban water infrastructure.

\section{References}

[1] Diario La Verdad. Especial Riada del Guadalentin 29/09/2012. Editorial Grupo Vocento, 2012.

[2] García-Ayllón S. \& Tomás A. Actions, diagnosis and territorial management of the disaster in the city of Lorca after earthquake of May 11, 2011. Transactions on Information and Communication Technologies, Vol 47. ISSN: 1746-4463. WIT Press: Southampton, 2014. 
[3] Capel Molina, J.M. Génesis de las inundaciones de octubre de 1973 en el sureste de la Península Ibérica. Cuadernos geográficos de la Universidad de Granada, No4, 1974, pp. 149-166, ISSN 0210-546.

[4] European Commission. A new EU Floods Directive. Directive 2007/60/EC on the assessment and management of flood risks in all available languages OJ L288, 6.11.2007, p. 27.

[5] Ministerio de Agricultura, Alimentación y Medio Ambiente. Sistema Nacional de Cartografia de Zonas Inundables. http://www.magrama.gob.es

[6] García-Ayllón S. New analysis and diagnostic tools to improve governance in the context of urban planning and territorial management. International Journal of Sustainable Development and Planning. WIT Press: Southampton, 2014. 